\title{
Plasma cefazolin levels during cardiovascular surgery: Effects of cardiopulmonary bypass and profound hypothermic circulatory arrest
}

Anthony D. Caffarelli, MD, ${ }^{a}$ Jeff P. Holden, MD, ${ }^{b}$ Ellen Jo Baron, PhD, D (ABMM), ${ }^{c}$ Harry J. M. Lemmens, MD, PhD, Holly D'Souza, BS, MT (ASCP), ${ }^{c}$ Vincent Yau, BS, ${ }^{c}$ Cornelius Olcott IV, MD, ${ }^{d}$ Bruce A. Reitz, MD, ${ }^{a}$ D. Craig Miller, MD, and Pieter J. A. van der Starre, MD, PhD

From the Departments of Cardiothoracic Surgery, ${ }^{\mathrm{a}}$ Anesthesia, ${ }^{\mathrm{b}}$ Pathology, ${ }^{\mathrm{c}}$ and Vascular Surgery, ${ }^{\mathrm{d}}$ Stanford University, Stanford, Calif.

Received for publication July 31, 2005; revisions received Nov 3, 2005; accepted for publication Nov 21, 2005

Address for reprints: Anthony D. Caffarelli, MD, Department of Surgery, 300 Pasteur Dr, Room H3591, Stanford, CA 943055641 (E-mail: acaffare@ stanford.edu).

J Thorac Cardiovasc Surg 2006;131:1338-43 $0022-5223 / \$ 32.00$

Copyright (๑) 2006 by The American Association for Thoracic Surgery

doi:10.1016/j.jtcvs.2005.11.047
Objectives: We sought to assess the effects of cardiopulmonary bypass and profound hypothermic circulatory arrest on plasma cefazolin levels administered for antimicrobial prophylaxis in cardiovascular surgery.

Methods: Four groups (10 patients per group) were prospectively studied: vascular surgery without cardiopulmonary bypass (group A), cardiac surgery with a cardiopulmonary bypass time of less than 120 minutes (group B), cardiac surgery with a cardiopulmonary bypass time of greater than 120 minutes (group C), and cardiac surgery with cardiopulmonary bypass and profound hypothermic circulatory arrest (group D). Subjects received cefazolin at induction and a second dose before wound closure. Arterial blood samples were obtained preceding cefazolin administration, at skin incision, hourly during the operation, and before redosing. Cefazolin plasma concentrations were determined by using a radial diffusion assay, with Staphylococcus aureus as the indicator microorganism. Cefazolin plasma concentrations were considered noninhibitory at $8 \mu \mathrm{g} / \mathrm{mL}$ or less, intermediate at 16 $\mu \mathrm{g} / \mathrm{mL}$, and inhibitory at $32 \mu \mathrm{g} / \mathrm{mL}$ or greater.

Results: In group A cefazolin plasma concentrations remained greater than 16 $\mu \mathrm{g} / \mathrm{mL}$ during the complete surgical procedure. In group B cefazolin plasma concentrations diminished to $16 \mu \mathrm{g} / \mathrm{mL}$ or less in $30 \%$ of the patients but remained greater than $8 \mu \mathrm{g} / \mathrm{mL}$. In group $\mathrm{C}$ cefazolin plasma concentrations decreased to less than $16 \mu \mathrm{g} / \mathrm{mL}$ in $60 \%$ of patients and were less than $8 \mu \mathrm{g} / \mathrm{mL}$ in $50 \%$ of patients. In group D cefazolin plasma concentrations reached $16 \mu \mathrm{g} / \mathrm{mL}$ in $66 \%$ of the patients but decreased to $8 \mu \mathrm{g} / \mathrm{mL}$ in only 1 patient.

Conclusions: For patients undergoing cardiac surgery with a cardiopulmonary bypass time of greater than 120 minutes, a single dose of cefazolin before skin incision with redosing at wound closure does not provide targeted antimicrobial cefazolin plasma levels during the entire surgical procedure. Patients undergoing profound hypothermic circulatory arrest are better protected, but the described protocol of prophylaxis is not optimal.

$\mathrm{P}$ ostoperative infection in cardiac surgical patients, mainly caused by Staphylcoccus aureus and coagulase-negative staphylococci, ${ }^{1}$ is a cause of major morbidity and mortality. According to the National Heart, Lung, and Blood Institute-National Institute of Allergy and Infectious Diseases Working Group, cardiovascular infections caused by $S$ aureus are a serious national medical problem, with increases in the rate of $S$ aureus bacteremia ranging from $122 \%$ to $283 \%$ in individual hospitals. ${ }^{2}$

Antimicrobial prophylaxis with cephalosporin is used routinely to reduce surgical infections after cardiovascular surgery. The use of cardiopulmonary bypass 


\section{Abbreviations and Acronyms \\ $\mathrm{C}_{\mathrm{p}} \quad=$ plasma cefazolin level \\ $\mathrm{CPB}=$ cardiopulmonary bypass}

(CPB), particularly in conjunction with profound hypothermic circulatory arrest (PHCA), causes substantial profound perturbations in hemodynamics, end-organ blood flow, and temperature. Because of these changes and their influence on antibiotic pharmacokinetics, the following investigation was undertaken to determine the effect of CPB and PHCA on cefazolin plasma levels administered for antimicrobial prophylaxis in patients undergoing cardiovascular surgery.

\section{Methods}

After obtaining the approval of the Stanford Institutional Review Board and individual written informed consent, a total of 40 patients were prospectively enrolled in the study and assigned to the following groups: group A, 10 patients undergoing vascular surgery (no $\mathrm{CPB}$ ); group $\mathrm{B}, 10$ patients undergoing cardiac surgery with a CPB time of less than 120 minutes; group C, 10 patients undergoing cardiac surgery with a CPB time of greater than 120 minutes; and group D, 10 patients undergoing cardiac surgery with the use of CPB and PHCA (Table 1).

In groups $\mathrm{B}$ and $\mathrm{C}$ the target systemic (bladder) temperature was $28^{\circ} \mathrm{C}$ to $30^{\circ} \mathrm{C}$. In group $\mathrm{D}$ the patients were systemically cooled during CPB to a tympanic membrane temperature of $20^{\circ} \mathrm{C}$. During the PHCA period, selective antegrade cerebral perfusion was supplied through a right axillary artery cannula, with a flow of $10 \mathrm{~mL} / \mathrm{kg}$ cold blood. Hydrocortisone $(1 \mathrm{mg} / \mathrm{kg})$, mannitol $(0.5$ $\mathrm{g} / \mathrm{kg}$ ), and thiopentone $(15 \mathrm{mg} / \mathrm{kg}$ ) were administered before the initiation of PHCA.

Other than the above mentioned differences, all participants received the same preoperative, operative, and postoperative care as nonparticipants.

Cefazolin, $1 \mathrm{~g}$ administered intravenously (first dose), was administered immediately after the induction of anesthesia, and a second dose was administered just before wound closure (second dose). In group A arterial blood samples drawn from a radial artery catheter were obtained before the first cefazolin dose, at skin incision, at every hour of surgical intervention, and just before the second dose of cefazolin. In groups B, C, and D additional samples were obtained before the initiation of $\mathrm{CPB}$, every hour during $\mathrm{CPB}$, and after weaning from CPB.

Blood samples were centrifuged, and serum was frozen to $-80^{\circ} \mathrm{C}$ before analysis. The antibiotic plasma level (in micrograms per milliliter) of cefazolin $\left(\mathrm{C}_{\mathrm{p}}\right)$ was then determined in vitro by using a biologic radial diffusion assay, with $S$ aureus as the indicator organism. ${ }^{3}$ Three levels of inhibition were identified: a $\mathrm{C}_{\mathrm{p}}$ of $32 \mu \mathrm{g} / \mathrm{mL}$ or greater was targeted as inhibitory to $S$ aureus, a Cp of $16 \mu \mathrm{g} / \mathrm{mL}$ was intermediate, and a $\mathrm{C}_{\mathrm{p}}$ of $8 \mu \mathrm{g} / \mathrm{mL}$ or less was considered to be not inhibitory.

Data are reported as means (standard deviation) and incidence of observations, unless indicated otherwise. Differences between groups were analyzed by using analysis of variance. The Tukey
TABLE 1. Types of operations by groups

\begin{tabular}{ll}
\hline Groups & \multicolumn{1}{c}{ Operations (n) } \\
\hline A & Abdominal aortic aneurysm repair (5) \\
& Thoracic aortic aneurysm (2) \\
& Aortofemoral bypass (2) \\
& Femoral-popliteal bypass (1) \\
B & Coronary artery bypass grafting (5) \\
& Aortic valve replacement (2) \\
& Mitral valve replacement (1) \\
& Tricuspid pulmonary valve replacement (1) \\
& Ascending aortic aneurysm (1) \\
& Aortic valve and ascending aortic aneurysm \\
& replacement (4) \\
C & Aortic, mitral, and tricuspid valve \\
& replacement (1) \\
& Aortic and mitral valve replacement (2) \\
& Aortic valve replacement and coronary artery \\
bypass grafting (2)
\end{tabular}

method was used for multiple comparisons. For each surgical group, Kaplan-Meier actuarial estimates were calculated to quantify the time from cefazolin administration to a decrease in concentration to less than 32,16 , and $8 \mu \mathrm{g} / \mathrm{mL}$; differences between curves were determined by using the log-rank test. All analyses were performed with S-PLUS version 6.2 software (Insightful Corp, Seattle, Wash).

\section{Results}

The demographic data of the patients are presented in Table 2. One patient in group D was removed from analysis because of surgical complications, including severe hemorrhage. There was no difference in age, body mass index, or preoperative serum creatinine value between the groups. In group $\mathrm{C}$ the temperature reached a significantly lower level $(P=.01)$, and the CPB time was significantly longer $(P<$ .01) than in group B. There was no difference in mean surgical time between groups A and B or between groups $\mathrm{C}$ and D. CPB and surgical times were significantly longer in groups $\mathrm{C}$ and $\mathrm{D}(P<.01)$ compared with that in group $\mathrm{B}$.

The plasma concentration time course of individual patients in each group is depicted in Figure 1. In group $\mathrm{A} \mathrm{C}_{\mathrm{p}}$ remained greater than $16 \mu \mathrm{g} / \mathrm{mL}$ during the complete surgical procedure. $\mathrm{C}_{\mathrm{p}}$ diminished to $16 \mu \mathrm{g} / \mathrm{mL}$ or less in $30 \%$ of the patients in group B, in $60 \%$ of the patients in group $\mathrm{C}$, and in $66 \%$ of the patients in group D. The Kaplan-Meier survival curves (Figure 2) show that in group $\mathrm{C}$ in $50 \%$ of the patients, $C_{p}$ reached plasma levels of $8 \mu \mathrm{g} / \mathrm{mL}$ or less, and in group $\mathrm{D}$ this was true in 1 patient. 
TABLE 2. Demographic data

\begin{tabular}{lcccc}
\hline Group $(\mathbf{n})$ & A (10) & B (10) & C (10) & D (9) \\
\hline Age $(\mathrm{y})$ & $66.9 \pm 10.6^{*}$ & $57.8 \pm 15.4$ & $50.1 \pm 16.8$ & $62.0 \pm 17.3$ \\
BMI (kg/m $\left.{ }^{2}\right)$ & $26.8 \pm 4.7$ & $24.5 \pm 4.6$ & $25.9 \pm 4.2$ & $24.8 \pm 3.5$ \\
Creatinine & $1.1 \pm 0.2$ & $0.9 \pm 0.1$ & $1.0 \pm 0.4$ & $1.0 \pm 0.3$ \\
Male/female sex (n) & $7 / 3$ & $7 / 3$ & $5 / 5$ & $6 / 4$ \\
CPB time (min) & $\mathrm{NA}$ & $109.4 \pm 24.2$ & $215.2 \pm 75.7$ & $216.7 \pm 55.6$ \\
Surgical time $(\mathrm{min})$ & $245.5 \pm 70.6$ & $299.5 \pm 70.0$ & $447.5 \pm 119.5$ & $500.0 \pm 104.0$ \\
Lowest temp $\left({ }^{\circ} \mathrm{C}\right)$ & $35.2 \pm 0.4$ & $30.8 \pm 1.7$ & $28.1 \pm 2.3$ & $21.2 \pm 0.5$
\end{tabular}

$B M I$, Body mass index; $C P B$, cardiopulmonary bypass; temp, bladder temperature. *Standard deviation.

Figure 2 shows the survival probabilities for concentrations greater than 32,16 , and $8 \mu \mathrm{g} / \mathrm{mL}$. Differences between groups $\mathrm{A}, \mathrm{B}, \mathrm{C}$, and $\mathrm{D}$ were not significant; however, there was a trend favoring a higher probability of concentrations greater than $32 \mu \mathrm{g} / \mathrm{mL}$ in group $\mathrm{D}(P=.08)$. In group $\mathrm{A}, \mathrm{B}$, $\mathrm{C}$, and $\mathrm{D}$ the median time for concentrations greater than 32 $\mu \mathrm{g} / \mathrm{mL}$ was $265,210,229$, and 349 minutes, respectively. All patients in groups A and B had concentrations greater

\section{Group A}

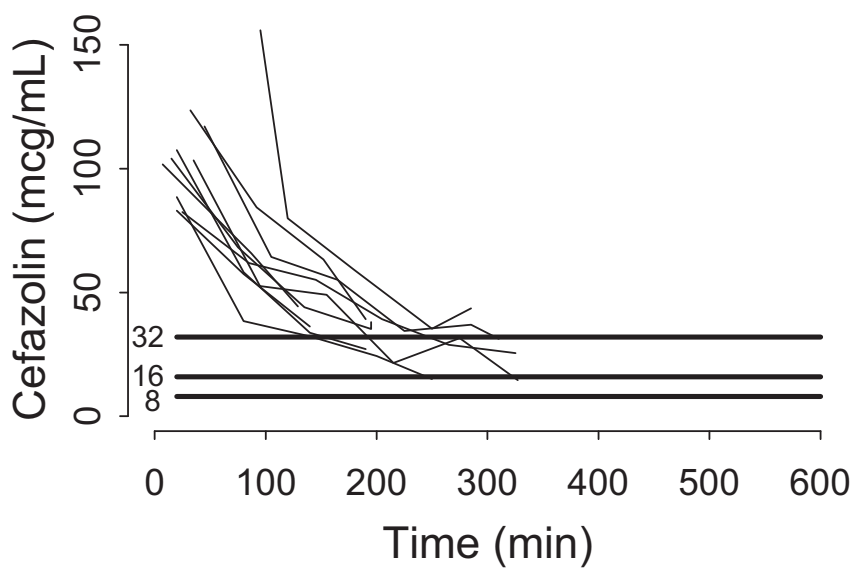

\section{Group C}

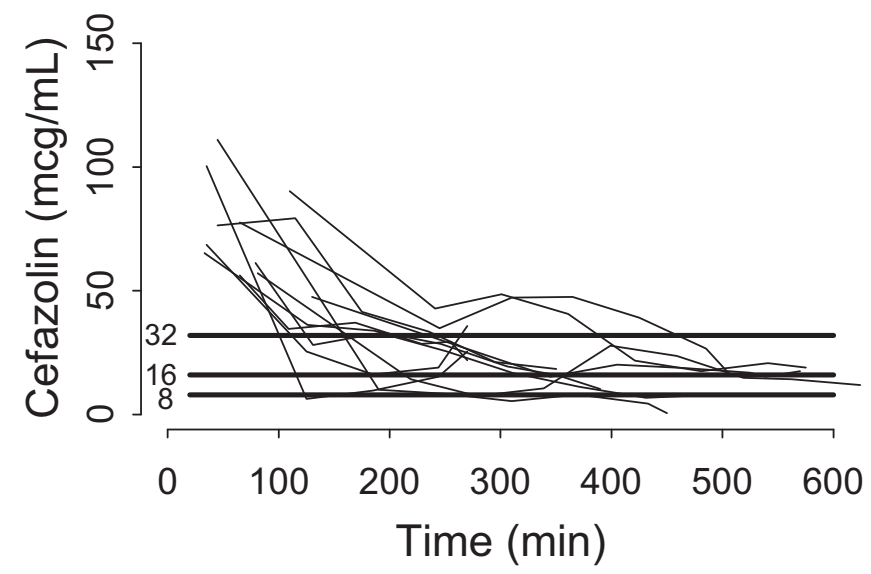

Group B

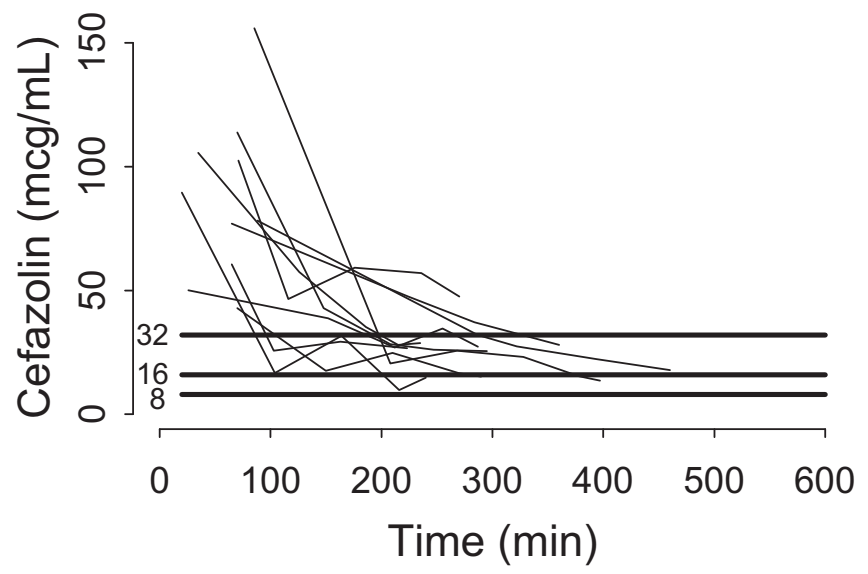

Group D

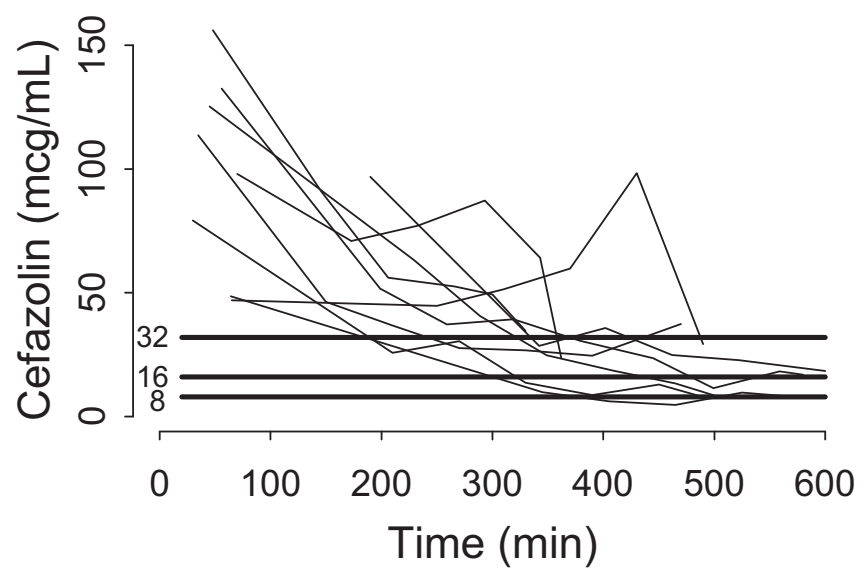

Figure 1. The cefazolin plasma concentration $\left(C_{p}\right)$ time course of individual patients in each surgical group. $A C_{p}$ of $8 \mu \mathrm{g} / \mathrm{mL}$ or less was considered to be not inhibitory, a $C_{p}$ of $16 \mu \mathrm{g} / \mathrm{mL}$ was considered to be intermediate, and a $C_{p}$ of $32 \mu \mathrm{g} / \mathrm{mL}$ or greater was considered to be inhibitory to $S$ aureus. 


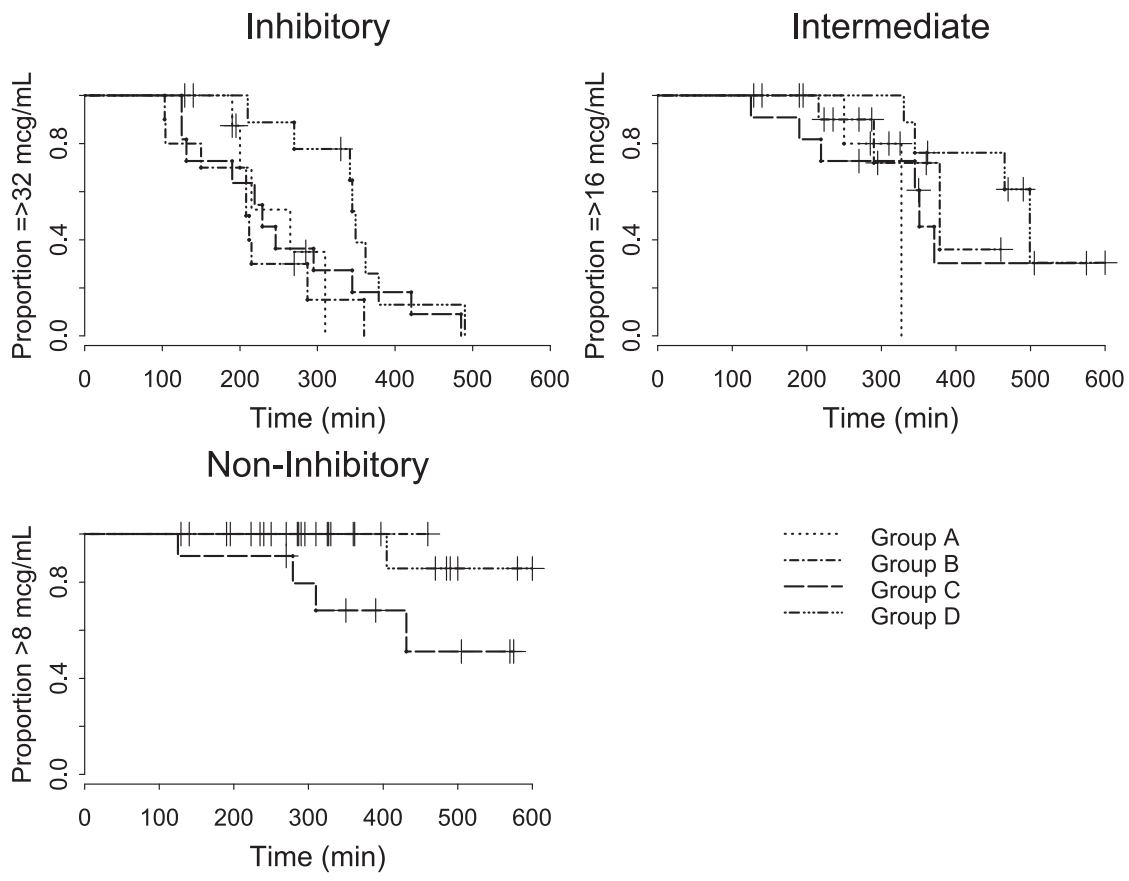

Figure 2. Kaplan-Meier survival curves for cefazolin concentrations greater than 32 , 16 , and $8 \mu \mathrm{g} / \mathrm{mL}$ in groups $\mathrm{A}, \mathrm{B}, \mathrm{C}$, and $\mathrm{D}$. than the noninhibitory level $(8 \mu \mathrm{g} / \mathrm{mL})$; however, in group D the probability of concentrations of greater than $8 \mu \mathrm{g} / \mathrm{mL}$ was $86 \%$ compared with group $\mathrm{C}$, in which the probability of concentrations greater than $8 \mu \mathrm{g} / \mathrm{mL}$ was only $51 \%$ before administration of the second dose of cefazolin.

\section{Discussion}

These observations demonstrate that $\mathrm{C}_{\mathrm{p}}$ is not changed by CPB times of less than 120 minute with mild-to-moderate hypothermia, but in procedures requiring prolonged $\mathrm{CPB}$ time ( $>120$ minutes) and PHCA, the dosing schedule used was not adequate to maintain targeted plasma concentrations of cefazolin.

The incidence of postoperative infection after cardiac surgery is reported to be between $7 \%$ and $18 \%$, including deep sternal wound infections between $1 \%$ and $3 \% .{ }^{4}$ Infection is associated with increased morbidity, mortality (up to $20 \%),{ }^{5}$ hospital stay, ${ }^{6}$ and costs. ${ }^{7}$ Toumpoulis and colleagues ${ }^{8}$ recently showed a 3 -fold increase in 10 -year mortality after initial recovery from deep sternal wound infection after coronary artery bypass surgery.

Cephalosporins, including cefazolin, are the most suitable prophylactic antibiotics because they are bactericidal, nontoxic, and active against the most common microorganisms, such as $S$ aureus, Staphylococcus epidermidis, and Enterobacter species. ${ }^{1,9}$ Cefazolin is $100 \%$ eliminated by the kidneys and $80 \%$ to $85 \%$ bound to protein. ${ }^{10}$ Pharmacokinetic parameters of cefazolin have been determined during surgical intervention by using a model-independent method, showing an elimination half- life of 231 minutes, a total body clearance of $1.05 \mathrm{~mL}$. $\mathrm{kg}^{-1} \cdot \mathrm{min}^{-1}$, and a steady-state volume of distribution of $243 \mathrm{~mL} / \mathrm{kg}$. ${ }^{11}$

The prophylactic dosing schedule of cefazolin remains controversial. The recommended dose in vascular and uncomplicated cardiac surgery is 1 to $2 \mathrm{~g}$ administered intravenously every 8 hours for 24 to 48 hours, ${ }^{12}$ although single preoperative dose prophylaxis is often used. Bucknell and associates ${ }^{13}$ showed that a single dose of cefazolin, $1 \mathrm{~g}$ administered intravenously, before incision was as effective as redosing during 48 hours in cardiac surgery cases with a short CPB time $(<120$ minutes). In more prolonged procedures (surgical time $>240$ minutes) intraoperative redosing of cefazolin appeared to be effective in reducing surgical infection, in which the second dose of cefazolin is usually administered at fixed intervals, ${ }^{14}$ instead of related to specific stages of the operative procedure, as in our study. Others administer a second dose of cefazolin immediately after the onset of $\mathrm{CPB},{ }^{4}$ arguing that the physiologic changes associated with $\mathrm{CPB}$ might rapidly decrease the effective plasma level of the drug. Naziri and coworkers ${ }^{15}$ proposed administering antibiotic prophylaxis continuously during surgical intervention to achieve constant plasma levels.

In our study the results show that the first dose of cefazolin was administered at the appropriate time before skin incision, as recommended, ${ }^{16}$ and the $\mathrm{C}_{\mathrm{p}}$ at incision time was inhibitory ( $\geq 32 \mu \mathrm{g} / \mathrm{mL}$ ) in all patients. Our choice of redosing just before wound closure has not been reported elsewhere. Our argument is based on the notion that during 
incision and skin closure, contamination of the wound is likely to occur. The reason for the timing of the last test sample was to verify whether our choice of redosing timing provided targeted plasma levels of cefazolin against microorganisms like $S$ aureus.

Group A was the control group because CPB is not needed during vascular surgical operations and cephalosporin pharmacokinetics are predictable. This study showed that within the time period assessed for group A, cefazolin plasma levels stayed in the therapeutic range for the most common gram-positive organism causing postoperative infection, suggesting that patients are well protected against $S$ aureus in accordance with earlier studies. ${ }^{17}$ In the 3 remaining groups, $\mathrm{CPB}$ was used. The effects of $\mathrm{CPB}$ on the pharmacokinetics of cefazolin might include changes in volume of distribution and protein binding, mainly caused by a decreased temperature, hemodilution, and changes in organ perfusion.

Group B patients were comparable with subjects in earlier investigations, including a relatively short CPB time and mild hypothermia. ${ }^{13}$ It is appropriate to compare group B with group A because age, body mass index, serum creatinine value, and surgical time were not statistically different. The results show that CPB with mild hypothermia does not change the plasma concentrations of cefazolin and that the dosing and timing schedule used kept the plasma cefazolin levels in the therapeutic range against $S$ aureus. The renal clearance of cefazolin, although not measured, is apparently preserved, which might be due to the effect of hemodilution, compensating for the lower temperature.

CPB time has not been examined often in earlier studies because the length of the surgical procedure is considered to be a more important risk factor for postoperative infection. ${ }^{14}$ Our approach of using a CPB time of greater than 120 minutes as risk factor is based on the premise that prolonged CPB might cause substantial organ dysfunction. This could lead to renal dysfunction and substantial fluid shifts. In group $\mathrm{C}$, with statistically longer $\mathrm{CPB}$ and operative times (both $P<.01$ ) and a lower mean minimal temperature $(P<.01)$ than in group $\mathrm{B}$, the results showed that cefazolin plasma levels decreased to intermediate therapeutic levels in $60 \%$ of the patients and to ineffective levels in 50\% of patients with respect to $S$ aureus prophylaxis. This indicates that our choice of redosing time in this group of patients was suboptimal. A CPB time of 120 minutes is apparently a cutoff point, and the expected decrease in cefazolin excretion rate does not occur but instead follows the normal time scale, despite the lower temperature.

Patients undergoing PHCA (group D) have not previously been studied with respect to antibiotic prophylaxis. Although the mean CPB and operation times in groups C and $\mathrm{D}$ were not significantly different, only 1 patient in group D had a completely subtherapeutic $(\leq 8 \mu \mathrm{g} / \mathrm{mL})$ plasma level. Thus PHCA changes the pharmacokinetics of cefazolin considerably more than merely long CPB time, shifting the curve of the plasma level to the right. This indicates that excretion of cefazolin is delayed and that PHCA prolongs the duration of targeted cefazolin plasma levels.

Several alternative prophylactic treatments for groups C and $\mathrm{D}$ can be proposed, including a higher initial dose (according to body weight; ie, $30 \mathrm{mg} / \mathrm{kg}$ cefazolin), a second dose at the onset of CPB, or redosing every 240 minutes. It can be predicted that all these dosing schedules will improve the efficacy of prophylaxis in these patients, but randomized comparative studies should elucidate which prophylaxis regimen is optimal, particularly for patients requiring prolonged $\mathrm{CPB}$ time.

This study has several limitations. We did not measure tissue levels of cefazolin, as is recommended by others, ${ }^{18}$ although tissue levels are reported to be directly related to cefazolin plasma levels. ${ }^{19}$ It might even be unclear whether the laboratory technique measuring effective plasma levels is accurate to predict risk of infection because Maki and colleagues ${ }^{20}$ observed $12 \%$ surgical wound infections after cardiac surgery in patients similar to our patients in group B in the presence of effective cefazolin plasma levels throughout surgical intervention. In our study surgical site infection was observed in 3 patients ( 1 in group B and 2 in group D), all with superficial infections and no cases of mediastinitis. Outcome studies with a larger number of patients would be needed to assess whether lower plasma levels of cefazolin in groups $\mathrm{C}$ and $\mathrm{D}$ actually correlated with a higher incidence of postoperative surgical site infections. Our choice for analyzing CPB time instead of surgical time as a discriminating factor can be criticized. It was mainly related to our routine to redose cefazolin at the start of wound closure and not to a fixed time interval.

We conclude that in patients undergoing long, complicated cardiac surgical procedures, our routine cefazolin prophylaxis schedule did not provide targeted plasma levels for all patients and that alternative techniques should be investigated, particularly in cardiac cases with moderate hypothermia and a prolonged CPB time.

\section{References}

1. L'Ecuyer PB, Murphy D, Little JR, Fraser VJ. The epidemiology of chest and leg wound infections following cardiothoracic surgery. Clin Infect Dis. 1996;22:424-9.

2. Lowy FD, Waldhausen JA, Miller M, Sopko G, Rosenberg Y, Skarlatos SI. Report of the National Heart, Lung and Blood Institute-National Institute of Allergy and Infectious Diseases working group on antimicrobial strategies and cardiothoracic surgery. Am Heart J. 2004;147:575-81.

3. Klassen M, Edberg SC. Measurements of antibiotics in human body fluids: techniques and significance. In: Lorian V, editor. antibiotics in laboratory medicine. 4th ed. Baltimore: Williams \& Wilkins; 1996. p. 230-9. 
4. Fellinger EK, Leavitt BJ, Hebert JC. Serum levels of prophylactic cefazolin during cardiopulmonary bypass surgery. Ann Thorac Surg. 2002;74:1187-90.

5. Milano CA, Kesler K, Archibald N, Sexton DJ, Jones RH. Mediastinitis after coronary artery bypass graft surgery. Risk factors and long-term survival. Circulation. 1995;92:2245-51.

6. Kappstein I, Schulgen G, Fraedrich G, Schlosser V, Schumacher M, Daschner FD. Added hospital stay due to wound infections following cardiac surgery. Thorac Cardiovasc Surg. 1992;40:148-51.

7. Asensio A, Torres J. Quantifying excess length of postoperative stay attributable to infections: a comparison of methods. J Clin Epidemiol. 1999;52:1249-56.

8. Toumpoulis IK, Anagnostopoulos CE, DeRose JJ Jr, Swistel DG. The impact of deep sternal wound infection on long-term survival after coronary artery bypass grafting. Chest. 2005;127:464-71.

9. Kreter B, Woods M. Antibiotic prophylaxis for cardiothoracic operations. Meta-analysis of thirty years of clinical trials. J Thorac Cardiovasc Surg. 1992;104:590-9.

10. Kalman D, Barriere SL. Review of the pharmacology, pharmacokinetics, and clinical use of cephalosporins. Tex Heart Inst J. 1990;17:203-15.

11. Lehot JJ, Reverdy ME, Etienne J, et al. Cefazolin and netilmicin serum levels during and after cardiac surgery with cardiopulmonary bypass. J Cardiothorac Anesth. 1990;4:204-9.

12. Osmon DR. Antimicrobial prophylaxis in adults. Mayo Clin Proc. 2000;75:98-109.
13. Bucknell SJ, Mohajeri M, Low J, McDonald M, Hill DG. Singleversus multiple-dose antibiotics prophylaxis for cardiac surgery. Aust N Z J Surg. 2000;70:409-11.

14. Zanetti G, Giardina R, Platt R. Intraoperative redosing of cefazolin and risk for surgical site infection in cardiac surgery. Emerg Infect Dis. 2001;7:828-31.

15. Naziri W, Cheadle WG, Trachtenberg LS, Montgomery WD, Polk HC Jr. Second place winner of the Conrad Jobst Award in the gold medal paper competition. Increased antibiotic effectiveness in a model of surgical infection through continuous infusion. Am Surg. 1995;61:11-5.

16. Classen DC, Evans RS, Pestotnik SL, Horn SD, Menlove RL, Burke JP. The timing of prophylactic administration of antibiotics and the risk of surgical-wound infection. N Engl J Med. 1992;326:281-6.

17. Edwards WH Jr, Kaiser AB, Kernodle DS, et al. Cefuroxime versus cefazolin as prophylaxis in vascular surgery. J Vasc Surg. 1992;15: 35-41.

18. Barza M. Pharmacokinetics of antibiotics in shallow and deep compartments. J Antimicrob Chemother. 1993;31(suppl D):17-27.

19. Bergamini TM, Polk HC Jr. Pharmacodynamics of antibiotic penetration of tissue and surgical prophylaxis. Surg Gynecol Obstet. 1989; 168:283-9.

20. Maki DG, Bohn MJ, Stolz SM, Kroncke GM, Acher CW, Myerowitz PD. Comparative study of cefazolin, cefamandole, and vancomycin for surgical prophylaxis in cardiac and vascular operations. A double-blind randomized trial. J Thorac Cardiovasc Surg. 1992;104:1423-34.

The Journal of Thoracic and Cardiovascular Surgery Conflict of Interest Policy

To assure fairness to authors submitting work for consideration in The Journal of Thoracic and Cardiovascular Surgery, a mechanism exists for managing conflicts of interest. The editor and each of the section editors complete a "Conflict of Interest" form that identifies any and all relationships with commercial and other academic entities. When the editor has a potential conflict because of a relationship with another entity or author, the editor appoints an alternate editor from among the section editors or editorial board members who assumes the entire responsibility for final decisions on the manuscript in question. The editor does not read the reviews that are submitted nor engage in discussing the manuscript prior to the final decision. When the conflict of interest involves a section editor, a "guest section editor" is appointed who fills the role normally played by the conflicted section editor. All members of the editorial board and reviewers are asked to indicate any conflict of interest when they agree to review a manuscript. 